\title{
A Case of Young Stroke due to Takayasu's Arteritis
}

\author{
Razzak MA', Badsha S', Rahman QAA ${ }^{3}$
}

DOI: https://doi.org/10.3329/jafmc.v14i2.45912

\section{Abstract}

The incidence of ischemic stroke among young adults is rising. Young individuals remain at high risk for recurrent stroke. As these patients generally still have a life expectancy of decades ahead, it is essential to find and educate them about the risk factors and causes of stroke to possibly prevent future vascular disease. One important but often missed cause of stroke in a young adult is Takayasu's Arteritis. Takayasu's Arteritis is a rare disease affecting the aorta and its main branches, causing arterial claudication and end-organ ischemia, including stroke. The etiology is unknown but is believed to be autoimmune. Early in the disease course, non-specific constitutional symptoms such as fever, malaise, and weight loss may occur this makes it a diagnostic challenge. Although, Takayasu's Arteritis generally follows an insidious course, acute presentation with visual loss or stroke may also occur. It can be adequately treated if it is identified early. We describe a case of a 20 -year-old officer cadet of Bangladesh Military Academy with no significant medical history who presented with acute ischemic stroke with right sided hemiplegia. He was evaluated as a young stroke case. Clinical examination revealed weak pulse in left upper limb and both carotids. Carotid bruits were also noted. CT angiogram findings revealed classical findings of Takayasu's Arteritis. He responded well with steroid and immunosuppressive agent (Methotrexate). However, ultimately he could not be retained in service because of extremely strenuous nature of training, residual disability and chronic progressive and incurable nature of the disease.

Key-words: Stroke, Young stroke, Takayasu's Arteritis, Carotid duplex study.

\section{Introduction}

Stroke in young adult or young stroke may be defined as neurological deficit suggestive of stroke in an individual between 18-50 years of age. Stroke in young adults are a major public health problem. It comprises $10-15 \%$ of all stroke patients. However, compared with stroke in older adults, stroke in the young has a disproportionately large economic burden by leaving victims disabled before their most productive years. Various factors and causes are associated with young stroke. Diabetes mellitus, dyslipidemia, smoking, hypertension, obesity, metabolic syndrome, sedentary lifestyle, genetic and familial factors are responsible for majority of strokes in $30 \mathrm{~s}$ and $40 \mathrm{~s}$. Other factors in $20 \mathrm{~s}$ and $30 \mathrm{~s}$ and older age groups include valvular heart disease, congenital heart disease like patent foramen ovale, infective endocarditis, cardiomyopathy, atrial fibrillation, prothrombotic conditions like antiphospholipid syndrome, protein $\mathrm{C}$, protein S, antithrombin III deficiency, factor $\mathrm{V}$ leiden, hematological malignancy, polycythemia rubra vera, sickle cell disease, SLE, coagulopathy, bleeding disorders, primary vasculitides, cerebral AV malformation, dissection of carotids, isolated cerebral vasculitis, illicit drugs like cocaine, anticoagulant and blood thinners, epilepsy, migraine, pregnancy, postpartum period, eclampsia, Moya Moya disease etc ${ }^{1}$. The incidence of young stroke has been increasing worldwide recently due to sedentary lifestyle, change in food habit and increased prevalence of obesity and metabolic syndrome.

We have diagnosed a 20 -year-old patient with ischemic stroke due to Takayasu's Arteritis in Department of Rheumatology, Combined Military Hospital (CMH) Dhaka on February 2017. This case report has been published as an eye-opener for the physicians regarding the various ways of presentation of Takayasu's Arteritis.

\section{Case Report}

A 20-year-old officer cadet of Bangladesh Military Academy was admitted to CMH Chattogram on 28 January 2017 with fever and vesicular skin rash for 5 days. Clinically he was diagnosed as a case of chicken pox and treatment was started with Tablet Acyclovir and other symptomatic management. On 1 February 2017 in early morning while he was in washroom, suddenly developed right sided hemiplegia and impaired consciousness. There was no headache, vomiting, convulsion, photophobia, difficulty in vision, palpitation, chest pain, shortness of breath, joint pain or weight loss. There was no history of hypertension, diabetes mellitus, rheumatic fever, valvular or congenital heart disease, atrial fibrillation, coagulopathy or vasculitis. Few weeks of training period at Bangladesh Military Academy prior to hospital admission were unremarkable. He was non-smoker and family history was not contributory. As the neurological condition deteriorated along with hypotension, he was started with ionotropic agent and Heli-evacuated to $\mathrm{CMH}$ Dhaka for better management.

At $\mathrm{CMH}$ Dhaka, he was evaluated as a young stroke. His both carotid pulses were weak and left brachial and radial pulses were barely perceptible, but regular. Carotid bruit was detected on both sides. His blood pressure on left arm was

1. Brig Gen Md Abdur Razzak, MBBS, MCPS, FCPS (Medicine), APLAR Fellow in Rheumatology, Professor and Head, Department of Medicine, AFMC 2. Maj Soleman Badsha, MBBS, Graded Specialist in Medicine, CMH, Barishal 3. Dr Quazi Audry Arafat Rahman, MBBS, Assistant Registrar, Department of Medicine, AFMC, FCPS Part II Trainee, Kurmitola General Hospital. 
$80 / 40 \mathrm{mmHg}$ and on right arm was $90 / 60 \mathrm{mmHg}$. He was investigated thoroughly. Routine investigations like CBC, RBS, lipid profile, ECG, CXR, and echocardiogram etc were within normal limit. CRP was positive. CT scan of brain (Figure-1) was done on 1/2/17 morning at $\mathrm{CMH}$ Chattogram which was unremarkable. But MRI of brain (Figure-2) at CMH Dhaka on the same day afternoon revealed fairly large infarct in left cerebral hemisphere and thereby confirmed the ischemic stroke. Further investigations were done to find out the cause. His RA factor, ANA anti-DS DNA, antiphospholipid antibody, c-ANCA, p-ANCA, VDRL, TPHA, HBsAg, Anti-HCV etc were negative PT, APTT were within normal limit.

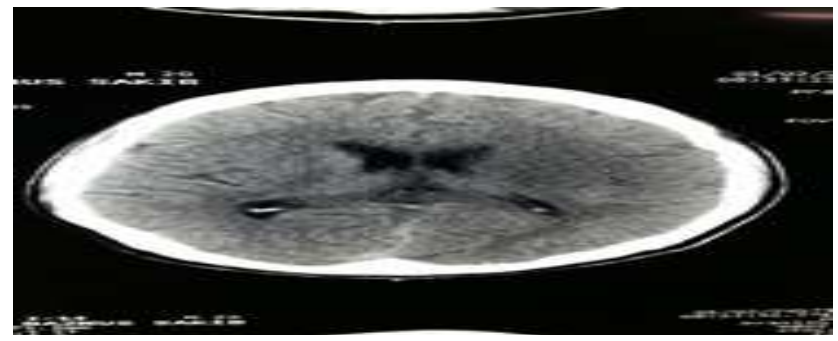

Figure-1: Unremarkable CT-Scan of Brain on 1/2/17 the morning

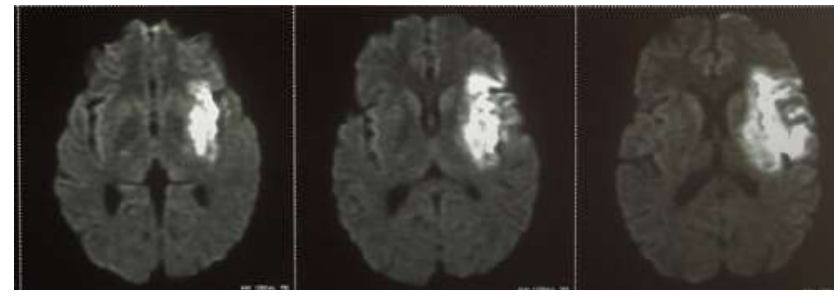

Figure-2: MRI of brain on 1/2/17 evening showing a large infarct at left cerebral hemisphere

On 2ebruary 2017 Carotid Duplex Study (Figure-3) showed bilateral diffuse atheromatous thrombus in common carotid artery with significant luminal narrowing and mild narrowing in both internal and external carotid arteries. CT Angiogram (contrast) of Arch of Aorta and neck vessels (Figure-4) revealed multilevel diffuse and segmental luminal irregularities and narrowing of Arch of the Aorta and its branches. Non visualization/luminal obliteration of common carotid arteries at different levels was suggestive of Takayasu's Arteritis.

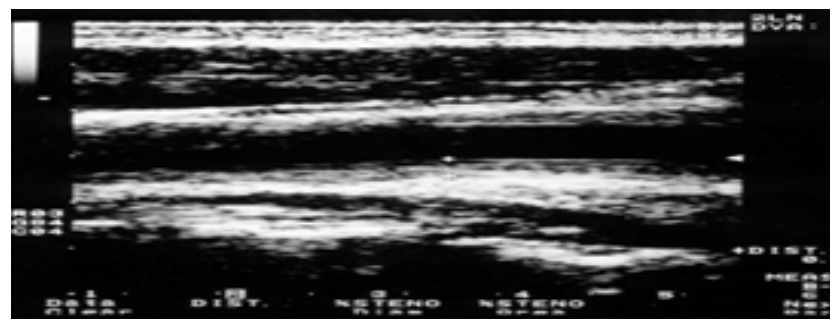

Figure-3: Carotid duplex study on 2/2/17 showing bilateral diffuse atheromatous thrombus in common carotid artery with significant luminal narrowing

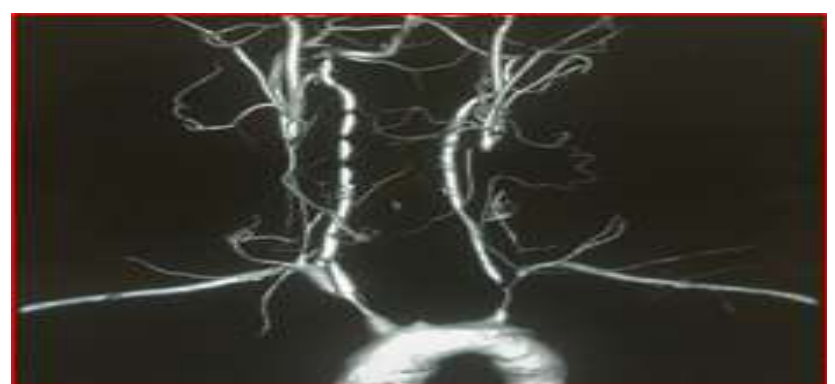

Figure-4: CT angiogram of Arch of Aorta and neck vessels on 5/2/17 showing multi-level diffuse and segmental luminal irregularities and narrowing of the arch of aorta and its branches

Therefore, finally he was diagnosed as a case of Takayasu's Arterits with Ischamic Stroke with right sided hemiplegia with chicken pox. He was treated with Injection Methyl Prednisolone 1gm IV once daily for 3 days followed by Tablet Prednisolone $1 \mathrm{mg} / \mathrm{kg}$ body weight daily for 6 weeks and then tapered down gradually. He was also given Injection Enoxaparin 40mg subcuteniously 12 hourly and Injection Acyclovir 500mg I/V 8 hourly for one week. Tablet Ecosprin and Pantoprazole were also given. Tablet Methotrax was added after subsidence of chicken pox, as immunosuppressive and steroid sparing agent. Calcium and Vitamin D supplementation was given. Adequate nutrition was ensured and supportive treatment, gradual passive and active exercise, physiotherapy and rehabilitation therapy were given. With the above treatment his condition gradually improved, and patient became ambulant within next 3 month period. However, he could not continue his service in Bangladesh Army because of some residual physical compromise following the stroke, inability to perform rigorous training activity and the progressive and incurable nature of the disease.

\section{Discussion}

Takayasu's Arteritis (also known as "aortic arch syndrome", "nonspecific aortoarteritis", "pulse less disease", 2 "occlusive thrombo aortopathy" and "Martorell syndrome") ${ }^{3}$ is a form of large vessel granulomatous vasculitis ${ }^{4}$ with an unknown etiopathogenesis with massive intimal fibrosis and vascular narrowing. It mainly affects the aorta and its branches, as well as the pulmonary arteries. Vessel inflammation leads to wall thickening, fibrosis, stenosis, and thrombus formation. More acute inflammation can destroy the arterial media and lead to aneurysm formation ${ }^{5}$. The inflammatory process is generally (but not exclusively) initiated in the second or third decade of life through the actions of non-inflammatory cells $\mathbf{s}^{6}$. Females are about 8-9 times more likely to be affected than males ${ }^{4}$. Female to male ratio appears to decline from Eastern Asia towards the West. It is a rare disease, but most commonly seen in Japan, South East Asia, India and Mexico ${ }^{5}$. Classification of Takayasu's arteritis has been made to classify the disease based on angiographic findings (Table-I \& Figure-5).

Takayasu's Arteritis also has some extravascular manifestations. Although the vascular manifestations of Takayasu's Arteritis are well known, the extravascular manifestations remain unclear. Some recent studies have addressed spondyloarthritis and inflammatory bowel disease in Takayasu's Arteritis patients. 
Moreover, peripheral arthritis has occasionally been observed in Takayasu patients ${ }^{7-10}$.

Table-l: Angiographic classification of Takayasu arteritis ${ }^{11}$

\begin{tabular}{|c|l|}
\hline Type & \multicolumn{1}{|c|}{ Vessel involvement } \\
\hline I & Branches from the aortic arch \\
\hline Ila & Ascending aorta, aortic arch and its branches \\
\hline Ilb & $\begin{array}{l}\text { Ascending aorta, aortic arch and its branches, thoracic } \\
\text { descending aorta }\end{array}$ \\
\hline III & $\begin{array}{l}\text { Thoracic descending aorta, abdominal aorta, and/or renal } \\
\text { arteries }\end{array}$ \\
\hline IV & Abdominal aorta and/or renal arteries \\
\hline V & Combined features of types llb and IV \\
\hline
\end{tabular}

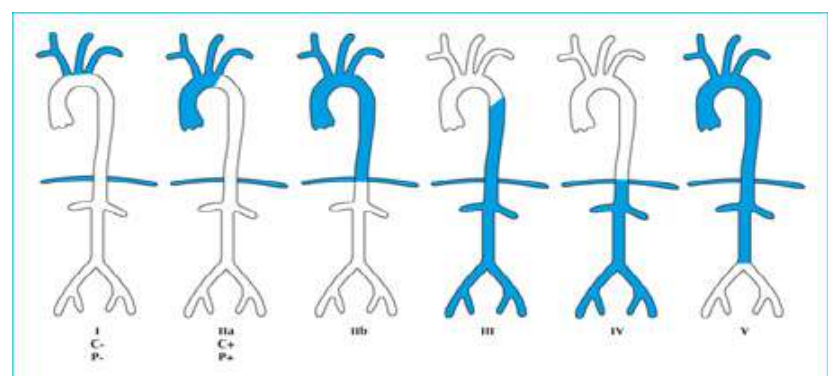

Figure-5: Angiographic classification of Takayasu arteritis

Symptoms reflect end organ ischemia. Non-specific features include fever, night sweats, malaise, weight loss, arthralgia, myalgia and mild anemia. As the inflammation progresses and stenoses develop, the more characteristic features become apparent, influenced by the development of collateral circulation ${ }^{12}$. Characteristic features of Takayasu's include diminished or absent pulse in $84-96 \%$ of patients associated with limb claudication and blood pressure discrepancies. Vascular bruits are found in $80-94 \%$ of patients, often multiple, and particularly affecting the carotids, subclavian, and abdominal vessels $^{13}$. Hypertension is present in $33-83 \%$ of patients ${ }^{14}$, generally reflecting renal artery stenosis, which is seen in 28$75 \%$ of patients ${ }^{15}$. There is presence of Takayasu retinopathy in up to $37 \%$ patients ${ }^{16}$. Congestive cardiac failure associated with hypertension, aortic regurgitation and dilated cardiomyopathy is seen in some cases ${ }^{17}$. Neurological features secondary to hypertension and/or ischemia, including postural dizziness, seizures, stroke and amaurosis. Pulmonary artery involvement is seen in $14-100 \%$ of patients depending on the method used to assess pulmonary vasculature ${ }^{18}$.

Neurological manifestations that may accompany Takayasu's Arteritis include headache, dizziness, visual disturbance, or loss of vision, transient ischemic attack (TIA), and stroke ${ }^{19}$. It has been reported that $10-20 \%$ of patients with Takayasu's Arteritis will have an ischemic stroke or a TIA ${ }^{20,21}$. Although cerebral ischemic attacks are not common complications of Takayasu's Arteritis, they can give rise to devastative neurological symptoms and be a major cause of morbid events and premature death ${ }^{22}$. A study to identify the mechanism of stroke in Takayasu's Arteritis patients found that hemodynamic compromise in large artery stenosis and thromboembolic mechanisms play significant roles in ischemic stroke associated with Takayasu' Arteritis. Few case reports of young strokes have been found worldwide in patients with Takayasu's Arteritis ${ }^{23}$. This patient adds to the list of young strokes with Takayasu's Arteritis.

Diagnosis of Takayasu's Arteritis can be made if at least 3 of the 6 ACR criteria are met (Table-II). Diagnosis is based on the demonstration of vascular lesions in large and middlesized vessels on angiography, CT scan, magnetic resonance angiography or FDG PET ${ }^{24}$. FDG PET can help in diagnosis of active inflammation not just in patients with active Takayasu arteritis prior to treatment but also in addition in relapsing patients receiving immunosuppressive agents ${ }^{25,26}$. Contrast angiography has been the gold standard. The earliest detectable lesion is a local narrowing or irregularity of the lumen. This may develop into stenosis and occlusion. The characteristic finding is the presence of "skip lesions," where stenosis or aneurysms alternate with normal vessels. Angiography provides information on vessel anatomy and patency but does not provide information on the degree of inflammation in the wall ${ }^{24}$.

The age at onset helps to differentiate Takayasu's arteritis from other types of large vessel vasculitis. For example, Takayasu's arteritis has an age of onset of $<40$ years, while giant cell arteritis has an age of onset $>60$ years $^{24}$. Takayasu arteritis is not associated with ANCA, rheumatoid factor, ANA, and anticardiolipin antibodies ${ }^{24}$.

Table-II: ACR criteria for the diagnosis of Takayasu arteritis ${ }^{27}$

\begin{tabular}{|c|c|}
\hline Criteria & Definition \\
\hline $\begin{array}{l}\text { Age at disease onset } \\
<40 \text { years }\end{array}$ & $\begin{array}{l}\text { Development of symptoms or findings related to } \\
\text { Takayasu arteritis at age }<40 \text { years }\end{array}$ \\
\hline of & $\begin{array}{l}\text { Development and worsening of fatigue and } \\
\text { discomfort in muscles of } 1 \text { or more extremity while } \\
\text { in use, especially the upper extremities }\end{array}$ \\
\hline tery puls & Decreased pulsation of 1 or both brachial arteries \\
\hline $\begin{array}{l}\text { lood pressure } \\
\text { ifference }>10 \mathrm{~mm} \mathrm{Hg}\end{array}$ & $\begin{array}{l}\text { of }>10 \mathrm{~mm} \mathrm{Hg} \text { in systolic blood pressure } \\
\text { rms }\end{array}$ \\
\hline Bruit over subclavian & $\begin{array}{l}\text { Bruit audible on auscultation over } 1 \text { or both } \\
\text { subclavian arteries or abdominal aorta }\end{array}$ \\
\hline $\begin{array}{l}\text { Arteriogram } \\
\text { abnormality }\end{array}$ & $\begin{array}{l}\text { Bruit audible on auscultation over } 1 \text { or both } \\
\text { subclavian arteries or abdominal aorta. } \\
\text { Arteriographic narrowing or occlusion of the entire } \\
\text { aorta, its primary branches, or large arteries in the } \\
\text { proximal upper or lower extremities, not caused by } \\
\text { arteriosclerosis, fibromuscular dysplasia, or similar } \\
\text { causes; changes usually focal or segmental }\end{array}$ \\
\hline
\end{tabular}

A diagnosis of Takayasu arteritis requires that at least 3 of the 6 criteria are met.

The differential diagnoses include other causes of large vessel vasculitis: inflammatory aortitis (syphilis, tuberculosis, lupus, rheumatoid arthritis, spondyloarthropathies, Behçet's disease, Kawasaki disease, and giant cell arteritis); developmental abnormalities (coarctation of the aorta and Marfan syndrome), and other aortic pathologies, such as 
ergotism and neurofibromatosis. Most of these have specific features that enable diagnosis ${ }^{28}$.

Medical treatment is to control active inflammation and minimize arterial injury. To prevent the development of vascular complications and induce remission, early initiation of immunosuppressive treatment is crucial ${ }^{29}$. Prednisolone is the first line agent, and the EULAR (European League Against Rheumatism) guidelines recommend an initial dose of $1 \mathrm{mg} / \mathrm{kg} /$ day (total maximum dose $60 \mathrm{mg} /$ day), with gradual tapering. Adjunctive steroid sparing immunosuppression is required in most patients to minimize steroid-related complications and control disease progression, particularly as there is considerable risk of relapse when steroid treatment is stopped. There are studies suggesting methotrexate and azathioprine are effective at inducing remission and halting progress of arterial lesions ${ }^{30}$. Promising results are achieved with mycophenolate and tocilizumab ${ }^{31}$. If treatment is not kept to a high standard, long-term damage or death can occur. Treatment should aim to control disease activity and preserve vascular competence, with minimal long-term side effects; those with disease that carries a good prognosis should not be put at risk by treatment that is more harmful than the disease itself ${ }^{6}$.

With symptomatic stenotic or occlusive lesions, it appears appropriate and often necessary to revascularize by stenting or bypass surgery. The indications for considering intervention include uncontrolled hypertension because of renal artery stenosis, severe symptomatic coronary artery or cerebrovascular disease, severe aortic regurgitation or coarctation, stenotic or occlusive lesions resulting in critical limb ischemia, and aneurysms at risk of rupture. In these cases, the risk benefit ratio for surgery is good ${ }^{32}$.

\section{Conclusion}

Takayasu's Arteritis is an autoimmune inflammatory disease of the arteries with slow and non-specific presentation which often evades early diagnosis due to its indolent and wide range of disease presentation. The patient presents with grave complications if the condition cannot be identified at an early stage. Late diagnosis can cause disabling or life-threatening complications. It is a systemic vasculopathy that can progress to cause vital organ ischemia; so once diagnosed, it requires long term follow up. Disease progression can be halted if the disease is diagnosed at an early stage. So, early diagnosis is paramount to avoiding grave complications, which requires a high index of suspicion and adequate awareness and knowledge of the physician. Patients can lead a healthy, near-normal life with early diagnosis and prompt treatment.

\section{References}

1. Alebeek MEV, Arntz RM, Ekker MS et al. Risk factors and mechanisms of stroke in young adults: The FUTURE study. Journal List,J Cereb Blood Flow Metab 2018; 38(9):PMC6120122

2. James W, Berger T, Elston D. Andrews' Diseases of the Skin: Clinical Dermatology. Saunders Elsevier, 2006. ISBN 978-0-7216-2921-6
3. Lupi-Herrera E, Sánchez-Torres G, Marcushamer J et al. Takayasu arteritis. Clinical study of 107 cases. Am Heart J 1977; 93:94-103.

4. American College of Physicians (ACP). Medical Knowledge Self-Assessment Program (MKSAP-15): Rheumatology. Systemic Vasculitis 2009:65-7.

5. Numano F, Okawara M, Inomata H et al. Takayasu's arteritis. Lancet 2000; 356:1023-5.

6. Setty HSN, Vijaykumar JR, Nagesh CM et al. Takayasu's arteritis - A comprehensive review. J Rare Dis Res Treat 2017; 2(2):63-6.

7. Gan FY, Fei YY, Li MT et al. The characteristics of patients having ankylosing spondylitis associated with Takayasu's arteritis. Clin Rheumatol 2014; 33:355-8.

8. Riviere E, Arnaud L, Ebbo M et al. Takayasu arteritis and spondyloarthritis: coincidence or association? A study of 14 cases. J Rheumatol 2017; 44:1011-7.

9. Kilic L, Kalyoncu U, Karadag $O$ et al. Inflammatory bowel diseases and Takayasu's arteritis: coincidence or association? Int J Rheum Dis. 2016; 19:814-8.

10. Terao C, Matsumura T, Yoshifuji $H$ et al. Takayasu arteritis and ulcerative colitis: High rate of co-occurrence and genetic overlap. Arthritis Rheumatol 2015; 67:2226-32.

11. Moriwaki R, Noda M, Yajima M et al. Clinical manifestations of Takayasu arteritis in India and Japan new classification of angiographic findings. Angiology 1997; 48:369-79.

12. Hall S, Barr W, Lie JT et al. Takayasu arteritis. A study of 32 North American patients. Medicine1985; 64:89-99.

13. Lupi-Herrera E, Sánchez-Torres G, Marcushamer J et al. Takayasu arteritis Clinical study of 107 cases. Am Heart J 1977; 93:94-103.

14. Hall S, Barr W, Lie JT et al. Takayasu arteritis A study of 32 North American patients. Medicine 1985; 64:89-99.

15. Jain S, Sharma N, Singh $S$ et al. Takayasu arteritis in children and young Indians. Int J Cardiol 2000; 75:S153-7.

16. Ishikawa K. Natural history and classification of occlusive thromboaortopathy Takayasu's disease. Circulation 1978; 57:27-35.

17. Subramanyan R, Joy J, Balakrishnan KG. Natural history of aortoarteritis Takayasu's disease. Circulation 1989; 80:429-37.

18. Sharma S, Kamalakar T, Rajani M et al. The incidence and patterns of pulmonary artery involvement in Takayasu's arteritis. Clin Radiol 1990; 42:177-82

19. Kim HJ, Suh DC, Kim JK et al. Correlation of neurological manifestations of Takayasu's arteritis with cerebral angiographic findings. Clin Imaging 2005; 29:79-85. 
20. Subramanyan R, Joy J, Balakrishnan KG. Natural history of aortoarteritis (Takayasu's disease) Circulation 1989; 80:429-437.

21. Kerr GS, Hallahan CW, Giordano Jet al. Takayasu arteritis. Ann Intern Med 1994; 120:919-29.

22. Pfefferkorn $\mathrm{T}$, Bitterling $\mathrm{H}$, Hüfner $\mathrm{K}$ et al. Malignant hemispheric infarction in Takayasu arteritis. J Neurol 2008; 255:1425-6.

23. Hwang J, Kim SJ, Bang OY et al. Ischemic Stroke in Takayasu's Arteritis: Lesion Patterns and Possible Mechanisms. J Clin Neurol 2012; 8(2):109-115.

24. Watts RA, Scott DG et al. Vasculitis in Clinical Medicine, 2010.

25. Kiyoshi S; Masuyama T, Masatomi I et al. FDG-PET of Takayasu's Arteritis. Journal of General Internal Medicine 2014; 29(7):1072-3.

26. Daisuke T, Go H, Takashi I et al. Role of FDG PET-CT in Takayasu Arteritis. JACC: Cardiovascular Imaging 2012; 5(4):422-9.

27. Arend WP, Michel BA, Bloch DA et al. The American College of Rheumatology 1990 criteria for the classification of Takayasu arteritis. Arthritis Rheum 1990; 33:1129-34.
28. Johnston SL, Lock RJ, Gompels MM et al. Takayasu arteritis: A review. J Clin Pathol 2002; 55(7):481-6.

29. Maksimowicz-McKinnon K, Clark TM, Hoffman GS. Limitations of therapy and a guarded prognosis in an American cohort of Takayasu arteritis patients. Arthritis and Rheumatism. 2007; 56(3):1000-9.

30. Mukhtyar C, Guillevin L, Cid MC et al. EULAR recommendations for themanagement of large vessel vasculitis. Annals of the Rheumatic Diseases 2009; 68(3):318-23.

31. Ambrish $S$ et al. Efficacy and Safety of Tocilizumab in Treatment of Takayasu Arteritis: A Systematic Review of Randomized Controlled Trials. Atherosclerosis Supplements 2018; 32:121-2.

32. Fields CE, Bower TC, Cooper LT et al. Takayasu's arteritis operative results and influence of disease activity. Journal of Vascular Surgery 2006; 43(1):64-71. 